\title{
Mechanism of Immobilized Protein A Binding to Immunoglobulin G on Nanosensor Array Surfaces
}

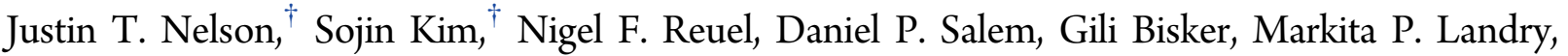 \\ Sebastian Kruss, Paul W. Barone, Seonyeong Kwak, and Michael S. Strano*
}

Department of Chemical Engineering, Massachusetts Institute of Technology, Cambridge, Massachusetts 02139, United States

ABSTRACT: Protein A is often used for the purification and detection of antibodies such as immunoglobulin G ( IgG) because of its quadrivalent domains that bind to the Fc region of these macromolecules. However, the kinetics and thermodynamics of the binding to many sensor surfaces have eluded mechanistic description due to complexities associated with multivalent interactions. In this work, we use a near-infrared (nIR) fluorescent single-walled carbon nanotube sensor array to obtain the kinetics of IgG binding to protein A, immobilized using a chelated $\mathrm{Cu}^{2+} /$ His-tag chemistry to hydrogel dispersed sensors. A bivalent binding mechanism is able to describe the concentration dependence of the effective dissociation constant, $K_{\mathrm{D}, \mathrm{eff}}$ which varies from $100 \mathrm{pM}$ to $1 \mu \mathrm{M}$ for IgG concentrations from $1 \mathrm{ng} \mathrm{mL} L^{-1}$ to $100 \mu \mathrm{g} \mathrm{mL}^{-1}$, respectively. The mechanism is shown to describe the unusual concentration-dependent scaling demonstrated by other sensor platforms in the literature as well, and a comparison is made between resulting parameters. For comparison, we contrast IgG binding with that of human growth hormone $(\mathrm{hGH})$ to its receptor $(\mathrm{hGH}-\mathrm{R})$ which displays an invariant dissociation constant at $K_{\mathrm{D}}=9 \mu \mathrm{M}$. These results should aid in the use of protein $A$ and other recognition elements in a variety of sensor types.
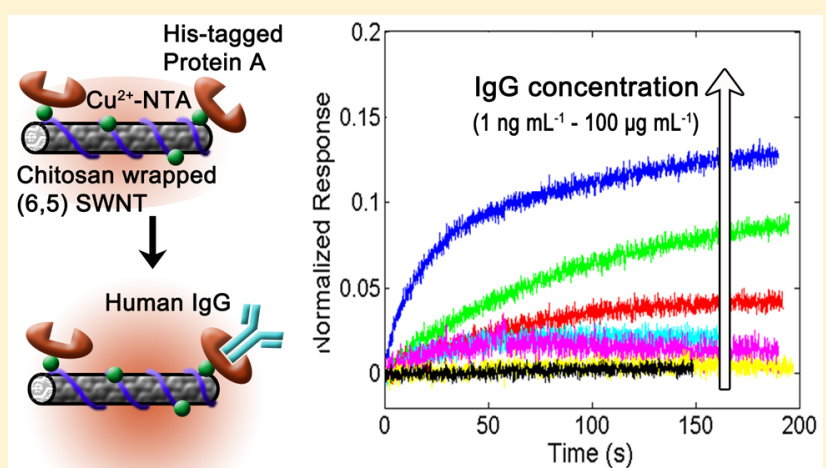

A ntibodies have emerged as a promising class of biological tools for therapeutic and diagnostic applications. ${ }^{1-5}$ Affinity chromatography is widely used for antibody recovery and purification; however, fundamental questions regarding the binding mechanisms involved in these processes still remain. ${ }^{6-8}$ For many classes of antibodies, protein A affinity chromatography is chosen due to the high affinity and selectivity that protein A has for antibodies such as human immunoglobulin $G$ (IgG). Protein A contains four structurally similar binding sites with high affinity for the $\mathrm{Fc}_{\mathrm{c}}$ region of most subclasses of human $\mathrm{IgG}$, and the Fc region of human IgG has two sites which can be bound by protein A.

Surface sensors such as surface plasmon resonance (SPR) and quartz-crystal microbalance (QCM), functionalized to display protein $\mathrm{A}$, are useful tools for immunoassays as they are capable of measuring kinetic and thermodynamic binding parameters. However, as a result of the multivalent nature of both protein $\mathrm{A}$ and human $\mathrm{IgG}$, analysis of such binding experiments is complicated and a meaningful interpretation of these parameters has been lacking. ${ }^{10}$ Others have measured apparent equilibrium binding affinities which demonstrate concentration dependence, with significantly greater affinity observed at low human IgG concentrations. ${ }^{6,7}$ These have been generally attributed to the multivalent interactions that are possible at large protein $\mathrm{A} / \mathrm{IgG}$ ratios; however, most techniques lack the sensitivity to measure interactions at very low IgG concentrations.
Herein we demonstrate a protein A-modified near-infrared (nIR) fluorescent single-walled carbon nanotube (SWNT) platform using a $\mathrm{Cu}^{2+} / N_{\alpha}, N_{\alpha}$-bis(carboxymethyl)-L-lysine hydrate (NTA)/histidine-tagged (His-tagged) protein mechanism. In general, His-tagged proteins strongly bind to divalent metal cations chelated to nitrilotriacetate groups, which provides a convenient chemistry for real-time label-free sensor applications. ${ }^{11-14}$ With this system, a calibration curve was prepared for picomolar to nearly micromolar IgG concentrations, and the binding dynamics were measured. From these data, we constructed a multivalent binding mechanism which is consistent with the kinetics and equilibrium state of binding. The mechanism described the unusual concentration-dependent scaling demonstrated by other sensor platforms in the literature, and a comparison is made between resulting parameters. To rule out the possibility that the sensor platform itself is nonlinear, human growth hormone ( $\mathrm{hGH}$ ) binding to its receptor protein (hGH-R) was also examined. This work highlights the necessity to consider binding models more complicated than the simple monovalent case when analyzing complex biologics.

Received: March 3, 2015

Accepted: July 6, 2015

Published: July 6, 2015 
a)

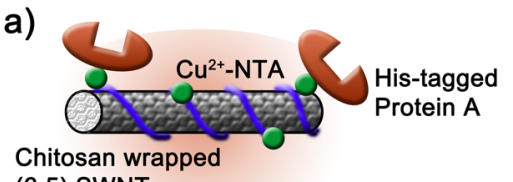

$(6,5)$ SWNT

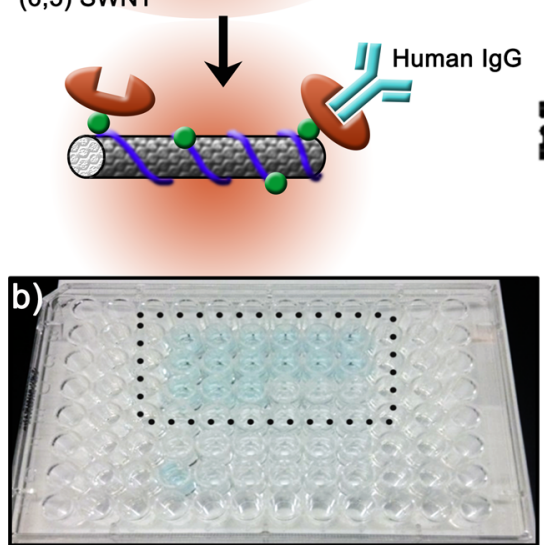

c)

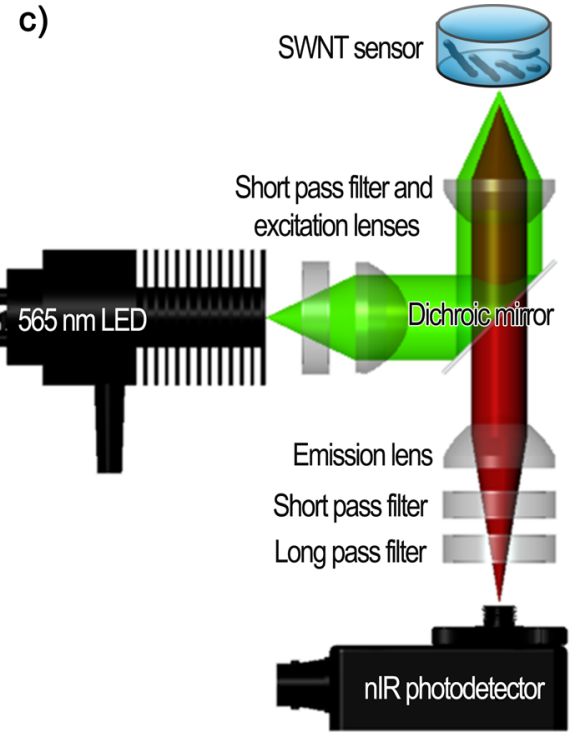

Figure 1. Description of sensor platform. (a) Schematic illustration of protein A-modified nIR fluorescent SWNT platform using a Cu ${ }^{2+}-N_{T A} / H_{i s-}$ tagged protein mechanism. (b) Photograph of sensors. Each well contains a SWNT-coated hydrogel which acts as the optical sensor. (c) Optical pathway of the detection system. A high-power $565 \mathrm{~nm}$ LED is filtered and collimated before being focused onto a single well (single sensor). The fluorescence emission is filtered and focused onto the nIR photodetector.

\section{EXPERIMENTAL SECTION}

Materials. Agarose and succinic anhydride were purchased from Bio-Rad Laboratories and Alfa Aesar, respectively. Raw HiPco SWNTs were bought from Unidym. The following chemicals were purchased from Sigma Aldrich: chitosan, sodium dodecyl sulfate (SDS), acetic acid, phosphate-buffered saline (PBS), $N$-ethyl- $N^{\prime}$-(3-(dimethylamino)propyl) carbodiimide hydrochloride (EDC), N-hydroxysuccinimide (NHS), copper(II) chloride dihydrate, and $N_{\alpha}, N_{\alpha}$-bis(carboxymethyl)L-lysine hydrate (NTA). Purified human IgG and recombinant protein A were purchased from Bethyl Laboratories and Sino Biological Inc., respectively. Recombinant human growth hormone $(\mathrm{hGH})$ and its receptor protein $(\mathrm{hGH}-\mathrm{R})$ were obtained from Novo Nordisk and ACRO Biosystems, respectively.

Chitosan-Wrapped SWNT Preparation. A gel-based separation was used to obtain high-purity $(6,5)$ SWNT suspended in $2 \%$ SDS. $^{15}$ In order to flocculate SWNT from the suspension, $15 \mathrm{~mL}$ of $5 \mathrm{mg} \mathrm{L}^{-1}$ SWNT/SDS suspension and $15 \mathrm{~mL}$ of methanol were mixed and shaken. The mixture was then centrifuged at $3200 \mathrm{~g}$ for $15 \mathrm{~min}$. The collected SWNT mass was dispersed in water and centrifuged several times to wash away residual SDS and methanol. After the final centrifugation, the SWNT mass was transferred to $10 \mathrm{~mL}$ of $2.5 \mathrm{mg} \mathrm{mL}^{-1}$ chitosan in water containing 1 vol \% acetic acid. The SWNTs were suspended via tip sonication at $10 \mathrm{~W}$ for 45 min. The resulting mixture was centrifuged two times at 16 $000 \mathrm{~g}$ for $1.5 \mathrm{~h}$ to remove SWNT aggregates. The resulting supernatant (containing the stable chitosan-wrapped SWNT suspension) was collected and used for sensor fabrication.

Sensor Fabrication. First, $2 \mathrm{mg} \mathrm{mL}^{-1}(0.2 \mathrm{wt} \%)$ of agarose was melted in water by heating until the solution became clear. Care was taken to avoid boiling. The solution was cooled to approximately $40{ }^{\circ} \mathrm{C}$, and $50 \mu \mathrm{L}$ of gel was deposited to the bottom of each well of a 96-well flat-bottomed plate. The gels were cured in a humid environment for $30 \mathrm{~min}$. Then, 15 $\mu \mathrm{L}$ of chitosan-wrapped SWNT solution $\left(5 \mathrm{mg} \mathrm{L}^{-1}\right)$ was spotted onto each gel and incubated in a humidified chamber at $37^{\circ} \mathrm{C}$. After $45 \mathrm{~min}$ of incubation, each well was gently washed with water to remove any excess SWNT solution.

Sensor functionalization was similar to the procedure outlined before. ${ }^{14}$ Briefly, $5 \mathrm{mg} \mathrm{mL} \mathrm{mL}^{-1}$ of succinic anhydride in $300 \mathrm{mM}$ PBS was added to each well and incubated overnight. After being washed with water, the carboxylic acids were activated with $20 \mathrm{mg} \mathrm{mL}^{-1} \mathrm{EDC}$ and $60 \mathrm{mg} \mathrm{mL}^{-1} \mathrm{NHS}$ in MES buffer for $2 \mathrm{~h}$. The wells were again washed with water. $\mathrm{Cu}-\mathrm{NTA}$ was then coupled to the NHS esters. ${ }^{12}$ The reaction was carried out in a HEPES buffer for $5 \mathrm{~h}$. The wells were washed with PBS and were ready for testing.

Sensor Testing. Sensors were equilibrated in $180 \mu \mathrm{L}$ of PBS and loaded with $20 \mu \mathrm{L}$ of the appropriate His-tagged receptor protein $\left(1 \mathrm{mg} \mathrm{mL}^{-1}\right.$ protein $\mathrm{A}$ for IgG binding, $100 \mu \mathrm{g}$ $\mathrm{mL}^{-1} \mathrm{hGH}-\mathrm{R}$ for hGH binding), as described before. ${ }^{16}$ The well was then washed with PBS to remove excess receptor protein. Binding was measured as $20 \mu \mathrm{L}$ of the desired analyte was added to the receptor-functionalized sensor. SWNT fluorescence intensity was monitored for the duration of the experiment to record binding events in real time.

\section{RESULTS AND DISCUSSION}

Hydrogel Sensor Arrays Based on nIR Fluorescent Carbon Nanotubes. The sensor platform employed here is similar in approach to one that we have described previously with some modifications. ${ }^{11,13,14}$ The schematic illustration of sensor fabrication is shown in Figure 1a. First, agarose hydrogels are cast into each well of a 96-well polystyrene microplate. Fluorescent SWNTs wrapped in chitosan are adsorbed to the surface of each gel. The porous hydrogel serves to immobilize the SWNT in a three-dimensional network while accommodating diffusion of large antibodies to the sensors. The chitosan-wrapped SWNT are functionalized to display divalent metal cations which act as fluorescence modulators, as well as docking sites for hexahistidine-tagged (His-tagged) proteins. Copper was used as the divalent metal cation in this work which gave rise to the blue color seen in Figure $1 \mathrm{~b}$. His-tagged protein $\mathrm{A}$ is then loaded onto the sensors 
for detection of human IgG. Loading of protein A and subsequent binding to human IgG both cause increases in SWNT fluorescence intensity by displacing the position of the copper ions.

A simplified nIR fluorescence detection system was also built to monitor SWNT fluorescence intensity in real time (Figure 1c). The optical pathway is similar to that of an inverted microscope. A visible LED is used as the excitation source for the SWNTs, and an InGaAs transimpedence amplified photodetector is used to monitor the nIR fluorescent signal. The resulting binding curves are similar to sensorgrams obtained from other commercialized techniques such as SPR and biolayer interferometry (BLI-Forte Bio Octet) (Figure 2a). His-tagged protein $A$ is first loaded onto the sensors which

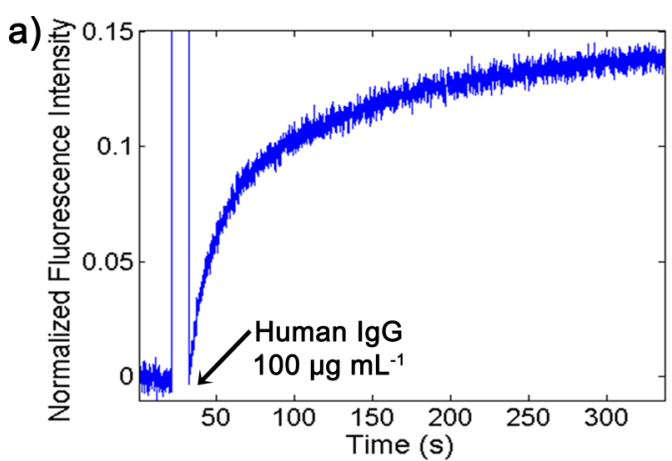

b)

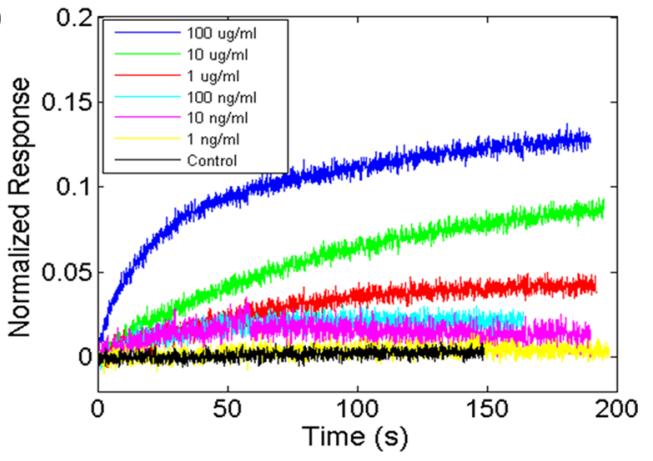

Figure 2. Sensor responses to IgG binding. (a) Example binding curve at $100 \mu \mathrm{g} \mathrm{mL}^{-1} \mathrm{IgG}$ concentration. (b) Sensor responses to IgG concentrations from $1 \mathrm{ng} \mathrm{mL}^{-1}$ to $100 \mu \mathrm{g} \mathrm{mL}^{-1}$. Response magnitudes and kinetics show strong concentration dependencies in this range.

are subsequently exposed to human IgG. Responses to human IgG were measured at concentrations of $100 \mu \mathrm{g} \mathrm{mL}^{-1}$ to $1 \mathrm{ng}$ $\mathrm{mL}^{-1}$, and a limit of detection of $10 \mathrm{ng} \mathrm{mL}^{-1}$ is achieved (Figure 2b). The sensor signal equilibrates within approximately $5 \mathrm{~min}$ at all concentrations, but response magnitudes and kinetics are easily distinguished.

Effective $K_{\mathrm{D}}$ Analysis. Several studies of protein A in the literature employ an effective $K_{\mathrm{D}}$ analysis whereby the binding of such a system is assumed to be monovalent in nature. ${ }^{6-8}$ To determine the effective dissociation constant, $K_{\mathrm{D} \text {,eff, the }}$ response curves are analyzed according to the scheme

$$
\operatorname{IgG}+\mathrm{PA} \stackrel{k_{\mathrm{f}} / k_{\mathrm{r}}}{\Longleftrightarrow} \mathrm{IgG}-\mathrm{PA}
$$

where IgG and PA are human IgG and protein A, respectively. $k_{\mathrm{f}}$ and $k_{\mathrm{r}}$ are forward and reverse rate constants, respectively. IgG-PA represents the bound complex of human IgG and protein $\mathrm{A}$ in the gel. The rate of formation of $\mathrm{IgG}-\mathrm{PA}$ is given by

$$
\frac{\mathrm{d}[\mathrm{IgG}-\mathrm{PA}]}{\mathrm{d} t}=k_{\mathrm{f}}[\mathrm{IgG}][\mathrm{PA}]-k_{\mathrm{r}}[\mathrm{IgG}-\mathrm{PA}]
$$

The total concentration of protein A binding sites, $[\mathrm{PA}]_{\mathrm{T}}$, is the sum of the concentration of the free and occupied sites. Therefore, the concentration of free protein A binding sites can be written as

$$
[\mathrm{PA}]=[\mathrm{PA}]_{\mathrm{T}}-[\mathrm{IgG}-\mathrm{PA}]
$$

Substituting eq 3 into eq 2 yields

$$
\begin{aligned}
\frac{\mathrm{d}[\operatorname{IgG}-\mathrm{PA}]}{\mathrm{d} t} & =k_{\mathrm{f}}[\operatorname{IgG}]\left([\mathrm{PA}]_{\mathrm{T}}-[\mathrm{IgG}-\mathrm{PA}]\right)-k_{\mathrm{r}}[\operatorname{IgG}-\mathrm{PA}] \\
& =k_{\mathrm{f}}[\operatorname{IgG}][\mathrm{PA}]_{\mathrm{T}}-k_{\mathrm{s}}[\mathrm{IgG}-\mathrm{PA}] \\
k_{\mathrm{s}}=k_{\mathrm{f}}[\operatorname{IgG}] & +k_{\mathrm{r}}
\end{aligned}
$$

We assume that the concentration of $\operatorname{IgG}$ is constant since the amount of IgG is much greater than the number of protein $\mathrm{A}$ binding sites. Additionally, we assume that the change in fluorescence intensity is proportional to the formation of IgGPA; therefore, eq 4 can be written as

$$
\frac{\mathrm{d}(I)}{\mathrm{d} t}=k_{\mathrm{f}}[\operatorname{IgG}]\left(I_{\max }\right)-k_{\mathrm{s}}(I)
$$

Integrating eq 6 yields

$$
I=\frac{k_{\mathrm{f}}[\operatorname{IgG}]\left(I_{\max }\right)}{k_{\mathrm{f}}[\operatorname{IgG}]+k_{\mathrm{r}}}\left(1-\mathrm{e}^{-k_{\mathrm{s}} t}\right)+I_{0}
$$

The normalized response $(R)$ is then given by

$$
R=\frac{I-I_{0}}{I_{\max }}=\frac{k_{\mathrm{f}}[\operatorname{IgG}]}{k_{\mathrm{f}}[\operatorname{IgG}]+k_{\mathrm{r}}}\left(1-\mathrm{e}^{-k_{\mathrm{s}} t}\right)
$$

At equilibrium, the exponential term goes to zero and the response is expressed as

$$
R_{\mathrm{eq}}=\frac{k_{\mathrm{f}}[\mathrm{IgG}]}{k_{\mathrm{f}}[\operatorname{IgG}]+k_{\mathrm{r}}}
$$

The effective equilibrium dissociation constant, $K_{\mathrm{D} \text {,eff }}$ is defined as

$$
K_{\text {D,eff }}=\frac{k_{\mathrm{r}}}{k_{\mathrm{f}}}
$$

Substituting eq 10 into eq 9 gives eq $11 . K_{\mathrm{D} \text {,eff }}$ can then be calculated from the normalized response, as shown in eq 12 .

$$
\begin{gathered}
R_{\mathrm{eq}}=\frac{[\operatorname{IgG}]}{[\operatorname{IgG}]+K_{\mathrm{D}, \mathrm{eff}}} \\
K_{\mathrm{D}, \mathrm{eff}}=[\mathrm{IgG}] \frac{1-R_{\mathrm{eq}}}{R_{\mathrm{eq}}}
\end{gathered}
$$

Using eq $12, K_{\mathrm{D} \text {,eff }}$ was calculated for each $\mathrm{IgG}$ concentration and is shown in Figure $3 \mathrm{~b}$. It is observed that $K_{\mathrm{D} \text {,eff }}$ strongly depends on IgG concentration, an effect that has been previously reported with other binding platforms. Ogi et al. observed dissociation constants of $10^{-11}-10^{-7} \mathrm{M}$ over a similar range of human IgG concentrations from QCM measurements. ${ }^{6}$ Saha et al. reported a dissociation constant of $3.44 \times$ $10^{-8} \mathrm{M}$ for nanomolar IgG concentrations, but noted that higher IgG concentrations do not fit the same $K_{\mathrm{D}}$ as lower 

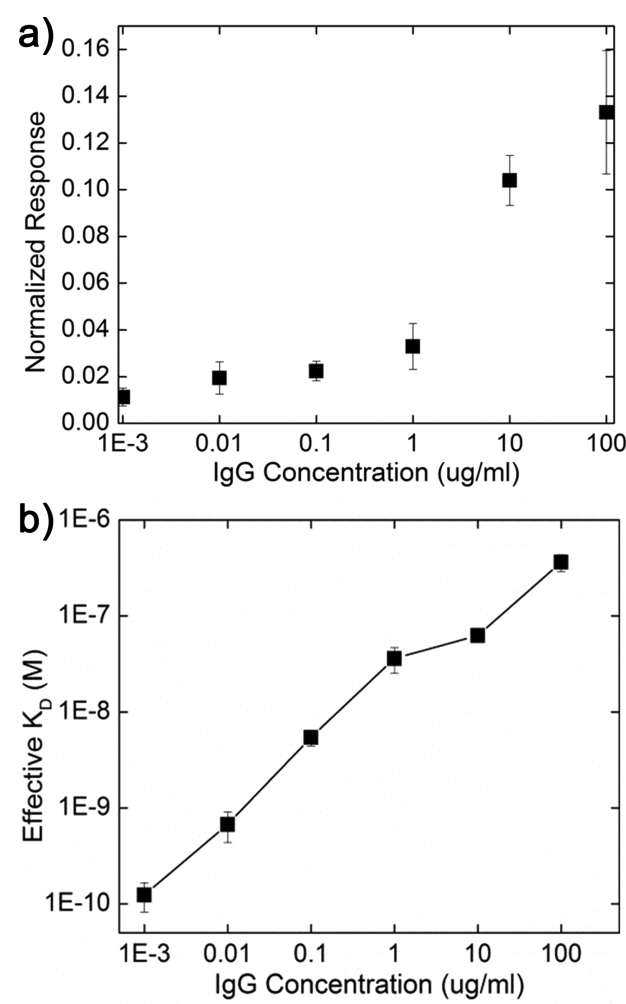

Figure 3. (a) Calibration curve of the normalized equilibrium responses at each IgG concentration. (b) Effective $K_{\mathrm{D}}$ measurements showing strong concentration dependence, with enhanced apparent affinity at lower IgG concentrations.

concentrations. ${ }^{7}$ This concentration-dependent $K_{\mathrm{D}}$ is also reported in human thyroid stimulating hormone. ${ }^{17}$

A Bivalent Mechanism. Protein A forms different binding structures with IgG depending upon the ratio of protein $A$ and IgG present. ${ }^{6,7}$ IgG contains two protein A-binding domains, and protein A contains four IgG-binding domains. ${ }^{18,19}$ However, one can mathematically demonstrate that any number of univalent binding sites on the protein A can be modeled as one average site, without loss of mechanistic description and yielding a concentration invariant $K_{\mathrm{D}}$. If we assume protein $\mathrm{A}$ has $n$ different univalent binding sites, each with a different dissociation constant, the reaction network is given by $n$ reactions analogous to 13 .

$$
\operatorname{IgG}+\mathrm{PA} \underset{K_{\mathrm{D} i}}{\Leftrightarrow} \operatorname{IgG}-\mathrm{PA}_{i}
$$

The total number of binding sites is

$$
\mathrm{PA}+\sum_{i=1}^{n} \mathrm{IgG}_{-1} \mathrm{PA}_{i}=\mathrm{PA}_{\mathrm{T}}
$$

The equilibrium for this reaction can be described by the following equilibrium constant:

$$
\operatorname{IgG}-\mathrm{PA}_{i}=\frac{[\mathrm{IgG}][\mathrm{PA}]}{K_{\mathrm{D} i}}
$$

The normalized sensor response $(R)$ is given by the fraction of bound sites:

$$
\begin{aligned}
R_{\mathrm{eq}} & =\frac{\sum_{i=1}^{n} \mathrm{IgG}_{-} \mathrm{PA}_{i}}{\mathrm{PA}_{\mathrm{T}}} \\
& =\frac{\sum_{i=1}^{n} \mathrm{IgG}_{-} \mathrm{PA}_{i}}{\mathrm{PA}+\sum_{i=1}^{n} \mathrm{IgG}_{-} \mathrm{PA}_{i}} \\
& =\frac{\sum_{i=1}^{n} \frac{[\mathrm{IgG}][\mathrm{PA}]}{K_{\mathrm{D} i}}}{\mathrm{PA}+\sum_{i=1}^{n} \frac{[\mathrm{IgG}][\mathrm{PA}]}{K_{\mathrm{D} i}}}
\end{aligned}
$$

As shown in eq 12 , the effective $K_{\mathrm{D} \text {,eff }}$ is given by

$$
K_{\text {D,eff }}=[\operatorname{IgG}] \frac{1-R_{\mathrm{eq}}}{R_{\mathrm{eq}}}
$$

Substituting eq 16 into eq 17 yields

$$
K_{\mathrm{D}, \mathrm{eff}}=[\mathrm{IgG}] \frac{\mathrm{PA}}{\sum_{i=1}^{n} \frac{[\mathrm{IgG}][\mathrm{PA}]}{K_{\mathrm{D} i}}}=\frac{1}{\sum_{i=1}^{n} \frac{1}{K_{\mathrm{D} i}}}
$$

Equation 18 suggests that the effective dissociation constant does not display concentration dependence for an arbitrary number of univalent binding sites with different dissociation constants. Hence, the concentration-dependent $K_{\mathrm{D}}$ necessarily means that the mechanism is multivalent, involving two or more IgG or protein A molecules.

At relatively low IgG concentrations, a single IgG molecule can be bound twice by protein $A$ which results in a larger apparent affinity. At very high IgG concentrations, multiple IgG molecules can bind to a single protein $\mathrm{A}$, resulting in a lower apparent affinity. Therefore, the observed dissociation constant does not reflect the formation of a single structure, but instead reflects the apparent binding constant from a distribution of structures. Since each protein A-binding domain of human IgG can bind once to any of the four IgG-binding domains of protein A with nearly the same affinity, the only true thermodynamic binding constant for this pair is for univalent binding. We first consider this univalent interaction using a single-site adsorption model:

$$
\operatorname{IgG}+\mathrm{PA} \underset{K_{\mathrm{D} 1}}{\Leftrightarrow} \operatorname{IgG}-\mathrm{PA}
$$

The dissociation constant, $K_{\mathrm{D} 1}$, is given by

$$
K_{\mathrm{D} 1}=\frac{[\mathrm{IgG}][\mathrm{PA}]}{[\mathrm{IgG}-\mathrm{PA}]}
$$

The total concentration of protein A binding sites, $[\mathrm{PA}]_{\mathrm{T}}$, is the sum of the concentration of the free and occupied sites.

$$
[\mathrm{PA}]=[\mathrm{PA}]_{\mathrm{T}}-[\mathrm{IgG}-\mathrm{PA}]
$$

Substituting eq 21 into eq 20:

$$
[\mathrm{IgG}-\mathrm{PA}]=\frac{[\mathrm{IgG}][\mathrm{PA}]_{\mathrm{T}}}{[\mathrm{IgG}]+K_{\mathrm{D} 1}}
$$

As shown before, the normalized response is then given by

$$
R=\frac{[\mathrm{IgG}-\mathrm{PA}]}{[\mathrm{PA}]_{\mathrm{T}}}=\frac{[\mathrm{IgG}]}{[\mathrm{IgG}]+K_{\mathrm{D} 1}}
$$

Fitting our data to this univalent binding model indicates that $K_{\mathrm{D} 1}=30 \mathrm{nM}$ (Figure 4a); however, it is clear that low IgG concentrations are not fit well by this model. Therefore, it is crucial to understand the relationship between univalent and 

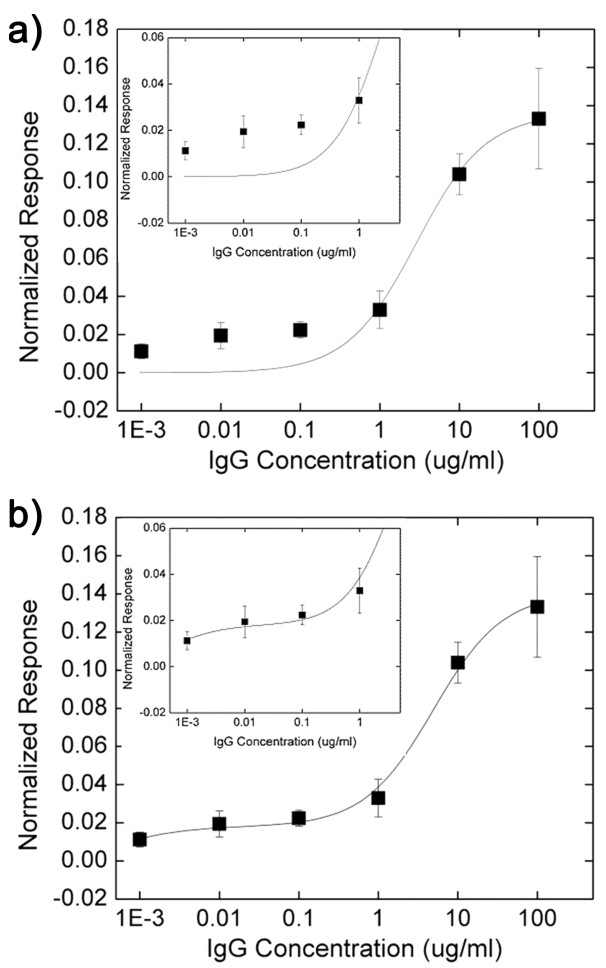

Figure 4. Comparison of human IgG-protein A binding models. (a) Univalent binding model which suggests $K_{\mathrm{D} 1}=30 \mathrm{nM}$. When the bivalency of IgG is neglected, the model fails to fit the behavior at low [IgG] (inset image). (b) Bivalent binding model. When the bivalency of IgG is accounted for, the model is able to predict the enhanced affinity observed at low [IgG] (inset image) while still fitting the results at high $[\mathrm{IgG}]$. As a result of the bivalency, this model reveals two binding constants: $K_{\mathrm{D} 1}=33 \mathrm{nM}$ and $K_{\mathrm{D} 2}=3.6 \mathrm{pM}$.

bivalent binding structures, and to determine when bivalent structures begin to significantly affect the observed binding constant.

To account for the bivalency of human IgG, we take a probabilistic approach which has been described previously. ${ }^{10,20}$ First, we define a fraction of bound IgG sites as parameter $f$. In our system, the numerator is simply the concentration of IgGPA structures, [IgG-PA]. The denominator is $2[\operatorname{IgG}]$ since we assume IgG concentration is approximately unchanged during the experiment and the valency of IgG is two. Therefore, $f$ can be expressed as the following:

$$
\begin{aligned}
f & =\text { fraction of bound IgG site } \\
& =\frac{[\text { bound IgG sites }]}{[\text { total IgG sites }]} \\
& =\frac{[\operatorname{IgG}-\mathrm{PA}]}{2[\mathrm{IgG}]}
\end{aligned}
$$

We then assume a binomial distribution between univalent and bivalent binding.

$$
\begin{aligned}
& \text { fraction of unbound } \operatorname{IgG}=(1-f)^{2} \\
& \text { fraction of univalently bound } \operatorname{IgG}=2 f(1-f) \\
& \text { fraction of divalently bound } \operatorname{IgG}=f^{2}
\end{aligned}
$$

Therefore, the ratio of univalent to bivalent $\operatorname{IgG}$ is

$$
\frac{\text { univalent }}{\text { bivalent }}=\frac{2 f(1-f)}{f^{2}}=\frac{2}{f}-2
$$

Substituting eqs 24 and 22 into eq 28, we can determine the ratio of binding types at any IgG concentration:

$$
\begin{aligned}
\frac{\text { univalent }}{\text { bivalent }} & =\frac{2}{f}-2 \\
& =\frac{4[\operatorname{IgG}]}{[\operatorname{IgG}-\mathrm{PA}]}-2 \\
& =\frac{4[\mathrm{IgG}]\left([\mathrm{IgG}]+K_{\mathrm{D} 1}\right)}{[\mathrm{IgG}][\mathrm{PA}]_{\mathrm{T}}}-2
\end{aligned}
$$

From eq 29, we see that, at high IgG concentrations (specifically $[\mathrm{IgG}] \sim K_{\mathrm{D} 1}$ ), this ratio grows linearly with [IgG], ultimately leading to a nearly univalent binding system which is accurately modeled by a single-site adsorption model. However, at low IgG concentrations $\left([\operatorname{IgG}] \ll K_{\mathrm{D} 1}\right)$, we see that the ratio approaches a constant. Therefore, the system is governed by a different $K_{\mathrm{D}}$ in this regime, one which incorporates bivalent binding. As mentioned above (Figure $4 \mathrm{a}$ ), the univalent binding constant $K_{\mathrm{D} 1}$ is approximately 30 $\mathrm{nM}$. Since IgG concentrations were tested from $70 \mathrm{pM}$ to 700 $\mathrm{nM}$, both binding regimes $\left([\mathrm{IgG}] \ll K_{\mathrm{D} 1}\right.$ and $\left.[\mathrm{IgG}] \sim K_{\mathrm{D} 1}\right)$ were encountered. It can be concluded that the solution is simply a sum of two independent binding models, as is used elsewhere: $^{21}$

$$
R=\frac{a_{1}[\mathrm{IgG}]}{[\mathrm{IgG}]+K_{\mathrm{D} 1}}+\frac{a_{2}[\mathrm{IgG}]}{[\mathrm{IgG}]+K_{\mathrm{D} 2}}
$$

The factors $a_{1}$ and $a_{2}$ are the normalized capacities for each binding type. Since it is likely that not all binding sites can support bivalent binding due to steric restrictions, we expect that $a_{2}$ is less than $a_{1}$. Fitting our data with this solution reveals $a_{1}=0.1225, a_{2}=0.01802, K_{\mathrm{D} 1}=33 \mathrm{nM}$, and $K_{\mathrm{D} 2}=3.6 \mathrm{pM}$ (Figure 4b). By inspection, it is clear that low IgG concentrations are fit much better by this model than the simple univalent model. It is noteworthy that the bivalent model is able to describe the low-concentration region of the IgG calibration curve. Despite being in the shallow section of the response curve, the model is able to extend accurate prediction of low IgG concentration, increasing its utility (Figure $4 b$, inset).

The $K_{\mathrm{D} \text {,eff }}$ values measured on our platform, along with the bivalent binding model, are shown with dissociation constants reported by others in Figure 5. Our results are consistent with previous reports. Ogi et al. observed similar concentration dependence, a trend which is approximated by our bivalent model. Saha et al. and Schwartz et al. reported similar dissociation constants at relatively high IgG concentrations which validate the results from our detection platform. Quantitative differences are likely due to source and quality of protein A and human IgG used, as well as the specific experimental conditions. To the best of our knowledge, this is the first attempt to provide a mathematical model to explain the unusual concentration-dependent scaling demonstrated by other sensor platforms in the literature.

Comparison to $\mathrm{hGH}$ as a Monovalent Analyte. To rule out the possibility that the sensor platform itself is nonlinear, leading to the concentration-dependent $K_{\mathrm{D}}$ shown in Figure $3 \mathrm{~b}$, we also examined hGH binding to its receptor, which is expected to be monovalent. An hGH binding assay itself also 


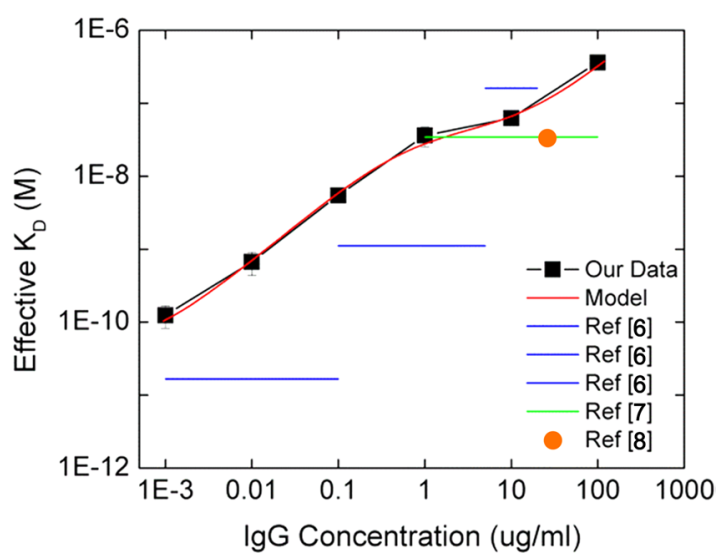

Figure 5. Comparison of $K_{\mathrm{D}}$ measurements between our sensor platform and other platforms featuring immobilized protein A. At large IgG concentrations, all platforms reveal a similar $K_{\mathrm{D}}$. At lower concentrations, the increased affinity observed by Ogi et al. (ref 6) is similar to what is observed in our platform. This trend is captured by the bivalent binding model.

has merit for potential measurement of drug potency, specifically for biopharmaceutical therapeutics. For example, techniques assessing protein activity vary based on the particular function of the protein, but often an animal model or cell-based assay is needed. Binding assays can sometimes be used as a surrogate measurement for activity if the assay is designed such that protein binding can be correlated to its activity. The standard for determining hGH activity, for example, is the hypophysectomized rat weight gain bioassay. ${ }^{22-24}$ This assay involves measuring the weight gain of hypophysectomized rats following multiple hGH injections per day for 10 days. Not only is this process time- and laborintensive, the results can vary by more than $50 \%$, requiring many replicate measurements to achieve a meaningful result. ${ }^{23}$ Since drug potency measurements are critical to biomanufacturing and pharmaceutical production, efforts have been made to develop assays which are suitable to replace the weight gain assay. These in vitro assays are based on measuring hGH binding to the extracellular binding domain of its native receptor (hGH-R) in an attempt to simulate the in vivo assay. One such set of assays is based on cellular proliferation of a cell line transfected to display $h \mathrm{GH}-\mathrm{R}$ on its surface. ${ }^{25}$ Proliferation after exposure to hGH for 1 day is shown to be dose-dependent with less variance than the weight gain assay. Another set of assays are based on hGH binding to hGH-R in solution and subsequent measurement of the extent of binding through chromatography. ${ }^{25}$ In this case, binding is again shown to be dose-dependent and correlates with the weight gain assay.

In this work, measurement of hGH binding to sensors functionalized with an hGH-R was performed using the same approach as above. In contrast to the multivalent binding behavior seen with human IgG, we demonstrate monovalent binding using $\mathrm{hGH}$ as the target analyte. We use a His-tagged extracellular binding domain of the native hGH receptor (hGH-R) as the immobilized binding partner. Sensor fabrication is similar to the His-tagged protein A-human IgG detection platform, with His-tagged hGH-R replacing protein A as the capture protein. Signal transduction is observed upon hGH-R loading and hGH binding. Concentration-dependent responses are observed as shown in Figure 6, and the normalized response magnitudes can be used to prepare a calibration curve.
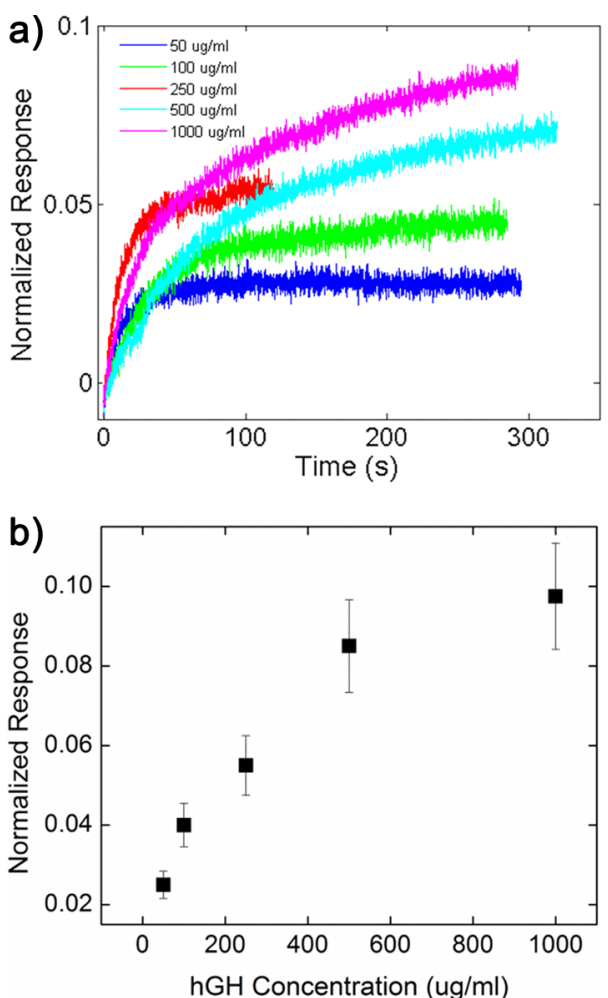

Figure 6. Measurements of hGH binding. (a) Sensor responses to hGH concentrations from 50 to $1000 \mu \mathrm{g} \mathrm{mL}^{-1}$. Response magnitudes are clearly concentration-dependent in this range. The variance in response kinetics is likely due to pipetting variability. (b) hGH calibration curve. Four replicate measurements were made at $1000 \mu \mathrm{g}$ $\mathrm{mL}^{-1}$, and this variance was used to estimate the variances at the lower concentrations.

In contrast to IgG, hGH binding to hGH-R in this system can be modeled by a single-site adsorption model. hGH:hGH$\mathrm{R}$ represents the bound complex of hGH and hGH-R in the gel. The dissociation constant, $K_{\mathrm{D}}$, is given by

$$
\begin{aligned}
& {[\mathrm{hGH}]+[\mathrm{hGH}-\mathrm{R}] \stackrel{K_{\mathrm{D}}}{\Leftrightarrow}[\mathrm{hGH}: \mathrm{hGH}-\mathrm{R}]} \\
& K_{\mathrm{D}}=\frac{[\mathrm{hGH}][\mathrm{hGH}-\mathrm{R}]}{[\mathrm{hGH}: \mathrm{hGH}-\mathrm{R}]}
\end{aligned}
$$

The total concentration of receptor sites, $[\mathrm{hGH}-\mathrm{R}]_{\mathrm{T}}$, is the sum of the concentration of free $\mathrm{hGH}-\mathrm{R}$ sites and that of occupied sites:

$$
[\mathrm{hGH}-\mathrm{R}]+[\mathrm{hGH}: \mathrm{hGH}-\mathrm{R}]=[\mathrm{hGH}-\mathrm{R}]_{\mathrm{T}}
$$

Substituting eq 33 into eq 32:

$$
K_{\mathrm{D}}=\frac{[\mathrm{hGH}]\left([\mathrm{hGh}-\mathrm{R}]_{\mathrm{T}}-[\mathrm{hGH}: \mathrm{hGH}-\mathrm{R}]\right)}{[\mathrm{hGH}: \mathrm{hGH}-\mathrm{R}]}
$$

The fraction of bound sites, $\theta$, is defined as

$$
\theta=\frac{[\mathrm{hGH}: \mathrm{hGH}-\mathrm{R}]}{[\mathrm{hGH}-\mathrm{R}]_{\mathrm{T}}}
$$

Substituting eq 35 into eq 34 : 


$$
K_{\mathrm{D}}=\frac{[\mathrm{hGH}](1-\theta)}{\theta}
$$

Solving for $\theta$ :

$$
\theta=\frac{[\mathrm{hGH}]}{K_{\mathrm{D}}+[\mathrm{hGH}]}
$$

As was done earlier, we assume that the fraction of bound sites is proportional to the normalized response of our sensors. Fitting eq 37 using nonlinear regression yields $K_{D}=9 \mu \mathrm{M}$ (Figure 7a).
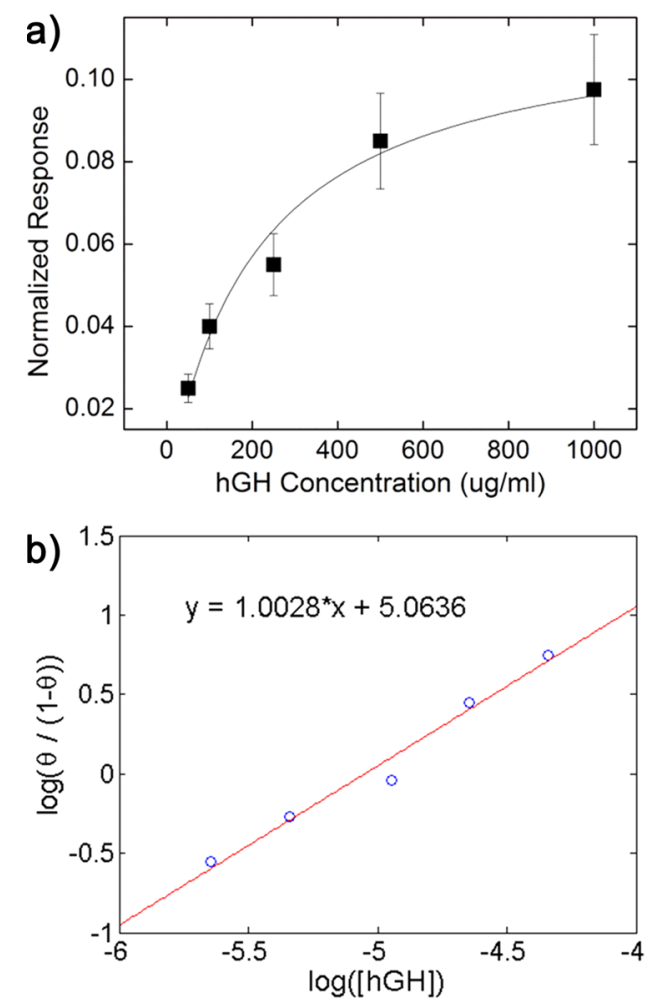

Figure 7. (a) hGH calibration curve with a single-site adsorption model, revealing $K_{\mathrm{D}}=9 \mu \mathrm{M}$. (b) Hill plot to determine cooperativity. The slope $=1.00$, indicating that cooperativity is not a factor in hGH binding in this system. The intercept $=5.06$, yielding $K_{\mathrm{D}}=8.6 \mu \mathrm{M}$.

Using this single-site adsorption model is only valid if cooperatively does not play a role in binding. Equation 37 can be written in the form of the Hill equation to determine if cooperativity is involved:

$$
\theta=\frac{[\mathrm{hGH}]^{n}}{K_{\mathrm{D}}{ }^{n}+[\mathrm{hGH}]^{n}}
$$

where $n$ is the Hill coefficient. If $n=1$, cooperative binding is not occurring and can be neglected. Equation 38 can be rewritten as

$$
\theta=\frac{1}{\left(\frac{K_{\mathrm{D}}}{[\mathrm{hGH}]}\right)^{n}+1}
$$

Inverting and rearranging yields

$$
\frac{1-\theta}{\theta}=\left(\frac{K_{\mathrm{D}}}{[\mathrm{hGH}]}\right)^{n}
$$

Inverting again and taking the log of both sides:

$$
\log \frac{\theta}{1-\theta}=n \log [\mathrm{hGH}]-n \log K_{\mathrm{D}}
$$

From eq 41, plotting $\log (\theta /(1-\theta))$ versus $\log [\mathrm{hGH}]$ should result in a line whose slope is $n$ and intercept is $-n \log \left(K_{\mathrm{D}}\right)$. In Figure 7 , the slope is very nearly 1 , indicating that cooperative binding does not play a role and can be neglected. The intercept indicates that $K_{\mathrm{D}}=8.6 \mu \mathrm{M}$, which is in good agreement with the value determined through nonlinear regression.

\section{CONCLUSION}

We have found that a bivalent binding model is necessary for mechanistic description of human IgG binding to immobilized protein A. A monovalent binding model, which is frequently used, fails to capture the unique binding behavior at low human IgG concentrations. In this regime, it is observed that the apparent affinity is enhanced, which we demonstrate is a result of multivalent interactions. We show that this model approximates data previously reported in the literature by others who have employed different sensor platforms. To our knowledge, this is first attempt to derive a mathematical model for explaining unusual concentration-dependent scaling demonstrated by other sensor platforms in the literature. In order to consider the possibility that the sensor platform itself is nonlinear, hGH binding to hGH-R was also examined. This pair is shown to have a monovalent interaction in our system, in contrast with IgG binding to protein A. This work elucidates the binding mechanism of human IgG to immobilized protein A and highlights the necessity to consider binding models more complicated than the simple monovalent case when analyzing complex biologics. These results provide better insight for use of protein $\mathrm{A}$ and other recognition elements in a variety of sensor types.

\section{AUTHOR INFORMATION}

\section{Corresponding Author}

*E-mail: strano@mit.edu. Phone: +1-617-324-4323. Fax: +1617-258-8224.

\section{Author Contributions}

${ }^{\dagger}$ J.T.N. and S.K. contributed equally to this work.

\section{Notes}

The authors declare no competing financial interest.

\section{ACKNOWLEDGMENTS}

This material is based upon work supported by the Defense Advanced Research Projects Agency (DARPA) and SPAWAR Systems Center Pacific (SSC Pacific) under contract no. N66001-13-C-4025. Any opinions, findings and conclusions or recommendations expressed in this material are those of the authors and do not necessarily reflect the views of the DARPA and SSC Pacific. This work was also supported by a contract from the National Science Foundation. N.F.R. and D.P.S. are grateful for a National Science Foundation Fellowship. The authors thank J. C. Love and K. Love for useful discussions.

\section{REFERENCES}

(1) Nelson, A. L.; Dhimolea, E.; Reichert, J. M. Nat. Rev. Drug Discovery 2010, 9, 767-774.

(2) Carter, P. J. Nat. Rev. Immunol. 2006, 6, 343-357.

(3) Borrebaeck, C. A. K. Immunology Today 2000, 21, 379-382. 
(4) Brennan, D. J.; O’Connor, D. P.; Rexhepaj, E.; Ponten, F.; Gallagher, W. M. Nat. Rev. Cancer 2010, 10, 605-617.

(5) El-Sayed, I. H.; Huang, X.; El-Sayed, M. A. Nano Lett. 2005, 5, 829-834.

(6) Ogi, H.; Motohisa, K.; Hatanaka, K.; Ohmori, T.; Hirao, M.; Nishiyama, M. Biosens. Bioelectron. 2007, 22, 3238-3242.

(7) Saha, K.; Bender, F.; Gizeli, E. Anal. Chem. 2003, 75, 835-842.

(8) Schwartz, M. P.; Alvarez, S. D.; Sailor, M. J. Anal. Chem. 2007, 79, 327-334.

(9) Surolia, A.; Pain, D.; Islam Khan, M. Trends Biochem. Sci. 1982, 7, 74-76.

(10) Nieba, L.; Krebber, A.; Plückthun, A. Anal. Biochem. 1996, 234, $155-165$.

(11) Ahn, J.-H.; Kim, J.-H.; Reuel, N. F.; Barone, P. W.; Boghossian, A. A.; Zhang, J.; Yoon, H.; Chang, A. C.; Hilmer, A. J.; Strano, M. S. Nano Lett. 2011, 11, 2743-2752.

(12) Wang, L.; Wei, L.; Chen, Y.; Jiang, R. J. Biotechnol. 2010, 150, $57-63$.

(13) Reuel, N. F.; Ahn, J.-H.; Kim, J.-H.; Zhang, J.; Boghossian, A. A.; Mahal, L. K.; Strano, M. S. J. Am. Chem. Soc. 2011, 133, 17923-17933.

(14) Reuel, N. F.; Grassbaugh, B.; Kruss, S.; Mundy, J. Z.; Opel, C.; Ogunniyi, A. O.; Egodage, K.; Wahl, R.; Helk, B.; Zhang, J.; Kalcioglu, Z. I.; Tvrdy, K.; Bellisario, D. O.; Mu, B.; Blake, S. S.; Van Vliet, K. J.; Love, J. C.; Wittrup, K. D.; Strano, M. S. ACS Nano 2013, 7, 74727482.

(15) Tvrdy, K.; Jain, R. M.; Han, R.; Hilmer, A. J.; McNicholas, T. P.; Strano, M. S. ACS Nano 2013, 7, 1779-1789.

(16) Reuel, N. F. Label-Free Carbon Nanotube Sensors for Glycan and Protein Detection. Ph.D. Thesis, Massachusetts Institute of Technology, Cambridge, Massachusetts, 2014.

(17) Ylander, P. J.; Hänninen, P. Biophys. Chem. 2010, 151, 105-110.

(18) Deisenhofer, J. Biochemistry 1981, 20, 2361-2370.

(19) Hanson, D. C.; Schumaker, V. N. J. Immunol. 1984, 132, 13971409

(20) Stevens, F. J. Mol. Immunol. 1987, 24, 1055-1060.

(21) Wang, Z.-X.; Jiang, R.-F. FEBS Lett. 1996, 392, 245-249.

(22) Evans, H. M.; Uyei, N.; Bartz, Q. R.; Simpson, M. E. Endocrinology 1938, 22, 483-492.

(23) Marx, W.; Simpson, M. E.; Evans, H. M. Endocrinology 1942, 30, $1-10$.

(24) Groesbeck, M. D.; Parlow, A. F. Endocrinology 1987, 120, 25822590.

(25) Roswall, E. C.; Mukku, V. R.; Chen, A. B.; Hoff, E. H.; Chu, H.; McKay, P. A.; Olson, K. C.; Battersby, J. E.; Gehant, R. L.; Meunier, A.; Garnick, R. L. Biologicals 1996, 24, 25-39. 